SECTION 3. Nanotechnology. Physics.

Sagat Zhunisbekov

doctor of technical Sciences, Professor, academician of the National Engineering Academy of the Republic of Kazakhstan, rector, Taraz technical Institute, Kazakhstan tar-ti@mail.ru

Igor Nikolayevich Meledin chemical engineer, Kazakhstan

\title{
NUCLEAR ENERGY IS BASIS OF POWER INDUSTRY OF KAZAKHSTAN IN THE FUTURE
}

\begin{abstract}
The authors of the article, "Nuclear energy is basis of power industry of Kazakhstan in the future" accentuate attention on the problems faced by Kazakhstan on issues of growth needs of industry and the public in energy resources. On the basis of extensive factual material available in generalized version present the maximum objective information about problems in the economy, general ecology and radioecology in deciding on how energy development in Kazakhstan.

Key words: thermal and electrical energy, atomic (nuclear) energy, environment, radiation factors, renewable, fusion energy, radioactivity, fusion, radio toxicity, scarce materials, cadmium, tellurium, radio phobia.
\end{abstract}

\section{ЯДЕРНАЯ ЭНЕРГЕТИКА - ОСНОВА ЭНЕРГЕТИЧЕСКОЙ ОТРАСЛИ КАЗАХСТАНА В БУДУЩЕМ}

Аннотация: Авторы в статье «Ядерная энергетика - основа энергетической отрасли Казахстана в будущем» приводят анализ тенденции развития энергетики в развитых странах, обращая внимание на возрастающую долю атомной энергетики. Акиентируют внимание на стоящих перед Казахстаном проблемах обеспечения роста потребности промышленности и населения в энергоресурсах. На основе сопоставления воздействия на окружаюшую среду атомных и тепловых электростанций, приводят фактические данные о преимуществах современных АЭС.

На основе имеющегося обширного фактического материала авторы убеждают в исключительной перспективности ядерной энергетики, надежности и экологичности современных, и, тем более, будущих ядерных энергетических установок. Авторы рассматривают данную статью, как доступную информацию для граждан по острым проблемам и задачам развития энергетики в Казахстане.

Ключевые слова: тепловая и электрическая энергия, атомная (ядерная) энергетика, экологическая безопасность, радиаџионные факторы, возобновляемые источники, термоядерная энергетика, радиоактивность, синтез, радиотоксичность, кадмий, теллур, радиофобия.

\section{Мнение специалистов}

Одним из главных показателей потенциала развития Казахстана, как и любого цивилизованного общества, является показатель его энерговооруженности. За предыдущую многовековую историю человечество смогло успешно развивать искусство, живопись, литературу, ваяние, музыку, медицину, даже строительство, но в техническом отношении человечество оставалось 
слабым. И только за последние сто с небольшим лет произошел огромный скачек в развитии технологии, позволивший за этот короткий промежуток времени пройти путь от аграрноремесленного производства до современных компьютерных технологий. Это стало возможным только после открытия и освоения электрической энергии. Уже даже на этом основании можно сделать вывод, что любое государство будет успешно развиваться только в том случае, если развитие энергетики будет опережать темпы развития других отраслей. Энергия - основа существования современного цивилизованного человечества.

Как показывают статистические данные, за последние 30 лет потребление электроэнергии в мире на душу населения удвоилось [1]. С учетом того, что население Земли увеличивается почти в геометрической прогрессии, такими же темпами будут расти и потребности в энергопотреблении, а значит, следует ждать огромного дефицита в энергоносителях, тепловой и электрической энергии. Мало того, в последние годы отмечается резкое увеличение энергопотребления в развивающихся странах, где сейчас проживает более трёх четвертей населения Земли. Этот дефицит тепловой и электрической энергии можно не предсказывать - он уже реально существует: многие государства, в том числе и Казахстан, вынуждены вводить нормативы потребления электроэнергии!

Увеличение производства тепловой и электрической энергий вырастает в проблему первостепенной важности. Проблема эта неразрывно связана с проблемой первичных источников энергии и определением основных направлений развития энергетики в целом. Любой современный человек представляет перечень первичных источников энергии: невозобновляемые органические носители энергии (уголь, нефть, природный газ, торф и т.п.), возобновляемые (нетрадиционные) источники энергии (ГЭС, солнечная, ветровая, приливная, геотермальная и др.) и атомная (ядерная) энергетика.

В настоящее время существует большое количество прогнозов глобального развития энергетики на ближайшее будущее, но практически все эксперты единодушны в том, что в ближайшие десятилетия человечество окажется перед фактом полного исчерпания резервов традиционных ископаемых источников энергии. Согласно этим же оценкам, мировые резервы невозобновляемых источников энергии (нефть, природный газ, торф и т. п.) уже в ближайшие годы не смогут обеспечить требуемый рост потребления энергии. И только запасы каменного угля, как источника первичной энергии, могут использоваться ещё около 150-200 лет [1].

Таким образом, перед человечеством стоит сложнейшая проблема неизбежного истощения природных энергоносителей. Эту задачу желательно решить без потери темпов развития экономики. Великий естествоиспытатель, геолог и философ двадцатого века В. И. Вернадский, посвятивший значительную часть своей жизни изучению закономерностей развития цивилизации на Земле, ещё в 1911 году сделал вывод: «ставка на использование исключительно органических видов топлива для развития энергетики - заведомо тупиковый путь». Примерно в то же время не менее великий химик Д.И. Менделеев заявил, что «... топить печь нефтью равносильно тому, что топить ассигнациями!»

Решение вопросов энергообеспечения населения и экономики будет зависеть от выбора верного направления развития энергетики.

Большинство высокоразвитых стран уже сделало выбор в направлении развития энергетики в пользу приоритетного развития атомной (ядерной) энергетики. Доля электроэнергии, полученной на атомных станциях, в мире неуклонно возрастает (сейчас в США-более $20 \%$, в Японииоколо $30 \%$, в Украине -50\%, в Швеции - 51\%, во Франции - около $80 \%$, в Литве - 100\% (до 1.01.10г.) произведённой энергии вырабатываются на АЭС) [8]. Например, соседний Китай в настоящее время строит 8 атомных энергоблоков, а в проекте - ещё 22. Из уже эксплуатируемых в настоящее время в мире реакторов (442) - более 150 реакторов действуют в Западной Европе, 120 в Северной Америке [6]. Сейчас в мире строится 30 атомных энергоблоков. Даже такие, хорошо обеспеченные органическими энергоносителями, страны как Ирак и Иран строят АЭС.

Необходимость развития атомной энергетики диктуется не только фактором истощения ресурсов органического происхождения. Не менее важным является степень воздействия способа 
производства энергии на здоровье населения и окружающую среду, т.е. фактор экологической безопасности.

Атомная энергетика, как это многим ни кажется неожиданным, обладает здесь явным преимуществом! При нормальных условиях эксплуатации она более безопасна для населения и окружающей среды, чем энергетика, основанная на сжигании органического топлива.

Сопоставляя воздействия на окружающую среду атомных и тепловых электростанций одинаковой электрической мощности, ученые получили поразительные данные: только радиационные выбросы угольных станщий в 10-20 раз опаснее, чем современной АЭС. И это без учёта выброса других вреднейших продуктов сгорания угля.

Выполненные в США оценки для угольной ТЭС мощностью 1 млн кВт показывают, что в течение года при её работе выделяется около 2 млрд. смертельных доз токсических веществ, которые распыляются в атмосфере и накапливаются в окружающей среде не разлагаясь. Годовая доза радиационного облучения населения в радиусе 20 км. от нормально работающей АЭС, замеренная на сотнях станций за последние 40 лет, оказалась в 20 раз ниже, чем в такой же зоне вокруг угольной ТЭС такой же мощности [1].

Кроме того, в обществе умалчиваются или «забываются» другие нежелательные, и даже опасные, явления, связанные с угольными ТЭС. Например, в нашей республике основу энергетики составляют тепловые угольные станции, работающие на Экибастузских углях. Специалистам известно, что этот уголь высокозольный, самого угля в нем всего около $35 \%$, остальное минеральные примеси - зола! При его сжигании в атмосферу ежегодно выбрасывается 17-19 миллионов тонн золы, которая содержит огромное количество загрязняющих и ядовитых веществ, в том числе и тонкодисперсных аэрозолей урана [5]. Эти выбросы покрывают огромные территории. Так, по сообщениям прессы, вредные аэрозольные выбросы Экибастузской ГРЭС фиксируются даже на территории западного Китая. На этих станциях в установленных золоуловителях оседает всего $20 \%$ золы, остальная масса вылетает в трубу. Но и выловленные в золоуловителях вредные отходы никак не утилизируются, и так же из отвалов разносятся ветром по окрестностям. По оценкам специалистов сейчас в золоотвалах накоплено более 300 миллионов тонн таких отходов! В том же Китае, который в основном отапливается углем, жизнь в северо-восточных провинциях почти каждую осень парализуется плотным смогом. Разве это не экологические проблемы, которые нужно срочно решать?!

Так, на примере Казахстана, замена угольной ТЭЦ мощностью 2000 МВт на эквивалентную АЭС приведет к сокращению потребления угля на 11,5 млн тонн в год; выбросов золы - на 3,6-4,9 млн тонн в год, углекислого газа - на 24,2-28,9 млн тонн в год, окиси серы - на 115 тыс. тонн в год, окиси азота - на 210 тыс. тонн в год и естественных радионуклидов - в 40 раз! [8].

В настоящее время в мире сжигается примерно 10 млрд. тонн условного топлива в год, на что расходуется около 35 млрд. тонн кислорода. Расчёты учёных-экологов показывают, что при сохранении этой ситуации, если будут сожжены разведанные запасы органического топлива, концентрация углекислого газа в атмосфере увеличится более чем вдвое [1,2]. При этом температура Земли, за счёт «парникового эффекта», повысится на 1-3 градуса, что приведёт к существенному изменению климата.

В этом вопросе даже не надо исследовать какие-то экологические модели и ходить к экстрасенсам. Сама природа уже подает однозначные сигналы неблагополучия. Даже за счет теперешнего незначительного повышения температуры Земли (всего на 0,7 градуса) увеличилось испарения мирового океана, и материки заливают небывалые дожди или заваливаются снегом. Возникающие при этом катастрофические снежные заносы и наводнения уносят человеческие жизни, парализуя транспорт и экономику некоторых государств. Показательный пример - небывалое наводнение в этом году на востоке России и севере Китая, которое продолжалось около 3-х месяцев! Мощность ураганов и их частота возросла в 2 раза [2]. Во многих регионах стали появляться несвойственные им 
опасные природные явления. Например, в России и Казахстане стали появляться невиданные ранее здесь разрушительные торнадо.

Одним из вариантов альтернативных источников энергии являются так называемые возобновляемые источники (энергия воды, ветра, морских приливов, солнечная энергия, геотермальные источники и т. п.), которые не дают выбросов парниковых газов в атмосферу. Но по заключению экспертов Мирового энергетического совета (МИЭРС), в обозримом будущем эти источники не будут экономически конкурентоспособными для крупномасштабного использования. МИЭРС утверждает, что даже при надлежащей финансовой поддержке, доля возобновляемых источников энергии в глобальном энергоснабжении к 2020 году не превысит $5 \%$ от потребного количества электроэнергии.

Анализ характеристик этих источников показывает, что их использование сможет решить лишь отдельные прикладные проблемы энергообеспечения на региональном уровне. О масштабном развитии гидроэнергетики для Казахстана говорить тоже не приходится. Уже сейчас ощущается дефицит воды просто для хозяйственных нужд.

Развитие солнечной энергетики потребует огромного количества очень дорогих и дефицитных материалов (приблизительно 60 тонн кадмия и 90 тонн теллура на батарею в 100 $\left.\kappa^{2}\right)$. Урон окружающей среде при производстве этих, далеко не безвредных в экологическом плане материалов для солнечных батарей, сведёт на нет кажущуюся экологическую чистоту этого вида энергии. Так, выбросы парниковых газов при производстве кремниевых элементов для солнечных батарей достигают весьма значительных величин, которые не принимаются в расчёт многими экологами.

На этом фоне во всем мире развивается атомная энергетика. Уже разработаны проекты атомных реакторов с гарантией полной безопасности, и которые способны практически полностью «сжигать» весь уран или торий при организации замкнутого топливного цикла с регенерацией отработавшего топлива, то есть увеличить выход энергии с того же количества урана в 200 раз!

Эксплуатация существующих, и даже уже строящихся реакторов, обеспечена топливом на многие сотни лет только на основе разведанных запасов урана. Кроме того, в недрах Земли и водах мирового океана находятся запасы урана, в тысячи раз превосходящие разведанные. Со временем человечество научится и этот уран экономически выгодно извлекать для своих нужд. В качестве топлива ядерных реакторов может быть использован и торий, запасы которого в недрах Земли в десятки раз больше, чем урана.

К тому же, сейчас идет активное развитие термоядерной энергетики, которая имеет ещё более обширные, практически безграничные, топливные ресурсы, и несравнимо меньший уровень радиационной опасности. Реакция синтеза лёгких ядер, сопровождающаяся колоссальным выделением энергии, может протекать почти без выхода нейтронов. Уровень радиоактивности такого реактора синтеза может быть в тысячи раз ниже, чем у современного реактора деления ядер, а возможность взрывного протекания реакций в нём практически исключена.

Еще один важный, экономический аспект. По оценкам МИЭРС, атомная электроэнергия заметно дешевле электроэнергии, выработанной на нефти, а также на угле и газе (сказываются высокие затраты на добычу и транспортировку органического топлива, которые будут возрастать). Другим важнейшим преимуществом ядерной энергетики является стабильность цен на электроэнергию в течение длительного периода времени. Структура затрат на производство электроэнергии в атомной энергетике существенно отличается от структуры формирования цен в других видах энергетики. Это связано с тем, что себестоимость атомной электроэнергии определяется в основном капитальными вложениями в строительство АЭС, а не топливными затратами, в отличие от нефти, газа и угля. Топливная составляющая в общей стоимости электроэнергии, вырабатываемой АЭС, не более $25 \%$, а для ТЭС, работающих на органическом топливе, на уровне 50-80\%. Данное обстоятельство приводит к повышенной устойчивости цены на атомную электроэнергию по отношению к колебаниям цены на топливо. Так, двукратное увеличение стоимости топлива (газ, уголь, уран) для себестоимости электроэнергии, вырабатываемой на этих 
энергоисточниках, приводит к увеличению себестоимости электроэнергии на АЭС на 9\%, на угольных ТЭС - на 31\%, на газовых - на 66\% [8].

Стабильность цен на электроэнергию в течение длительного периода времени создаст дополнительный важный фактор инвестиционной привлекательности Казахстана.

Уже в настоящее время мы видим явные преимущества ядерной энергетики. Сравнивая частоту несчастных случаев в различных отраслях трудовой деятельности человека, статистики убедились, что по этому показателю практическое использование атомной энергии занимает место в ряду со швейной, пищевой и ткацкой промышленностью. Причём доля радиационных аварий не превышает в этой цифре 10\% (включая чернобыльскую и фукусимскую аварии). Сопоставление потерь для общества (в виде числа смертельных случаев и дней нетрудоспособности) при различных видах производства электроэнергии опять говорит в пользу атомной энергетики.

В последнем заявлении МИЭРС сделан вывод: «Ядерная энергетика чрезвычайно важна, так как она является единственным источником энергоснабжения, имеющим уже весьма значительные и хорошо диверсифицированные ресурсы (возможно, неограниченные, если будут использоваться реакторы-размножители)... Фактически, в условиях угрозы изменения климата, ядерная энергия остаётся единственной энергетической технологией, которая может заменить уголь в режиме базисной нагрузки».

Экологически вредное воздействие угольных ТЭС и очень высокие капиталовложения, необходимые для его снижения, ставят угольные ТЭС в неконкурентоспособные условия. Для выработки одинакового количества электроэнергии требуются ежегодно добывать и перевозить 1,5-3 миллиона тонн органического топлива (нефти или угля) по сравнению с 200 тоннами уранового топлива [6].

Все аргументы противников атомной энергетики сводятся к одному - радиационной опасности. Болезненная и чрезмерно предвзятая реакция населения и части несведущих "специалистов" вызвана незнанием истинного положения дел. Боязнь радиоактивности, особенно широко распространившаяся после аварии на Чернобыльской АЭС и Фукусимы-1, благодаря фантастическим преувеличениям средствами массовой информации и необъективным освещением событий журналистами и политическими деятелями, постепенно перерастает в радиофобию.

«Сенсационные» сообщения о тысячах пострадавших от лучевой болезни, о мутациях животных в зоне Чернобыльской аварии, об увеличении числа заболеваний лейкемией у детей и т. п., послужило одной из главных причин обращения правительства СССР к МАГАТЭ с просьбой о проведении объективной международной экспертизы противоаварийных мероприятий и их результатов.

Двадцать известных в мире специалистов из десяти стран в течение 18 месяцев в 19901991 гг., проведя тысячи анализов и измерений, обобщив огромный объём фактического материала, написали отчёт, из которого следует, что многие факторы опасного воздействия на окружающую среду были значительно завышены!

Эти выводы подтверждены и свидетельствами японских специалистов из «Фонда изучения радиационных последствий в Хиросиме», где проходили тщательное обследование жители Чернобыля, в том числе и дети, приезжавшие в Японию по приглашению японских газет и «Ассоциации-помощи чернобылыцам», как жёртвы аварий. Эти выводы подтверждаются и новыми фактами благополучного многолетнего проживания людей, оставшихся в эвакуационной зоне.

С другой стороны, не многие знают, что добыча нефти и природного газа сопровождается подъёмом на поверхность Земли радиоактивных изотопов, в том числе, долгоживущих Ra-226 и Ra-228 с продуктами их распада [2,9]. Часто умалчивается факт накопления, даже еще при очистке нефти и газа, других экологически опасных материалов и элементов. Например, вокруг нефтерождений в западном Казахстане уже накоплено более миллиона тонн серы!

По данным Агентства по охране окружающей среды США на нефтяных и газовых месторождениях в штате Луизиана и других южных штатах нефте-водяная смесь, выкачиваемая 
на поверхность Земли, в 5-20 раз более радиоактивна, чем вода, которую разрешается сбрасывать с АЭС. В этом штате в водоёмах, в которые сбрасывалась вода после отделения её от нефти, концентрация радия на дне такая же, как на старых предприятиях по производству ядерного оружия!

О наличии подобных радиоактивных аномалий известно и на нефтепромыслах СНГ и Казахстана (месторождения Апшерона, Татарии, Калмыкии, Атырауской области, Мангышлака) [7]. В целом, по Казахстану на участках 22-х наиболее крупных месторождений, где сейчас производится добыча нефти, выявлено 267 участков радиоактивного загрязнения с мощностью дозы от 100 до17000 мкР/час (отметим, что при значениях 100 мкР/час и выше участки земли в пределах добычных полигонов рудников по требованиям Санитарных правил подлежат рекультивации).

Таким образом, по радиотоксичности, на единицу выработанной энергии нормально работающая АЭС оказывает на три порядка (в тысячу раз!) менышее воздействие на окружающую среду, чем нефтепромыслы [2].

Эксперты США посчитали, что если стандарты безопасности, утвержденные для из атомной промышленности, будут применяться в нефтяной и газовой, то стоимость дезактивации нефтяных и газовых месторождений будет достигать миллиарды долларов, а добыча нефти и газа окажется нерентабельной! [2].

Все приведённые факты указывают на то, что позиции атомной энергетики в плане охраны окружающей среды достаточно прочны.

Любому просвещённому человеку абсолютно ясно, что увеличение сложности производства влечёт за собой увеличение риска отказов и аварий. Лишние тому подтверждения — авария на химическом заводе в городе Бхопале (Индия), где произошла утечка смертоносного метилизоционата. В результате этой аварии погибло 2 тысячи и пострадало 100 тысяч человек, ущерб был оценён в 50 млрд. долларов США. Взрыв на газораспределительном заводе в городе Мехико (Мексика) унёс жизни 452-х человек, было ранено 4248 и пропало без вести 1000 человек $[1]$.

Известно, что аварии и несчастные случаи на транспорте ежегодно уносят сотни тысяч жизней людей во всех странах мира, эти цифры сопоставимы с потерями во время боевых действий! Однако эти аварии не приводят к требованиям общественности закрыть химические производства, газоперерабатывающие заводы, отказаться от использования скоростных видов транспорта, поскольку всем абсолютно ясно, что развитое общество не может существовать без топлива, продуктов химического производства и современных средств передвижения. Но может ли оно существовать и развиваться без современной энергетики?

Сегодня всё больше и больше приходит понимание того, что отказ от передовых технологий в любой отрасли будет означать либо замедление роста производства в целом, либо приведёт к дефициту продукции или энергии, что может обернуться значительно большими потерями, чем те, которые связаны с риском от внедрения этих технологий.

Очевидно, что количество новшеств во всех областях и сферах деятельности человечества будет лавинообразно возрастать, благодаря применению на практике результатов фундаментальных открытий в науке, использованию ранее неизвестных материалов и технологий. Освоению в производстве любых нововведений должен предшествовать этап детальнейшей проработки безопасных методов и приёмов ведения работ. Поэтому в настоящее время целесообразней прилагать все усилия на создание технологий с минимальным риском аварий, чем бороться с внедрением этих технологий в принципе.

Интересный и парадоксальный факт: благородная и гуманная борьба многих политических, общественных деятелей и организаций за прекращение испытаний ядерного оружия и уничтожение его во всём мире незаметно и всё больше перерастает у нас в борьбу с проектированием и строительством атомных станций и пунктов захоронения радиоактивных отходов, что никак не способствует подъему экономики, улучшению экологической и радиационной обстановки в стране. 
В этом плане нет отрасли более «многострадальной», чем атомная энергетика. Судить и будоражить общественное мнение о ее достоинствах, но в основном о ее надуманной особой опасности, берутся все «кому не лень». В основном - это политические и общественные деятели, работники СМИ, но никак не специалисты. При этом первые болыше озабочены своим имиджем радетелей за человечество, вторым нужна сенсация. Некоторые из них предлагают вопрос строительства объектов атомной энергетики в Казахстане вынести на всенародное обсуждение. Это совершенно несерьезно! Решение о путях развития такой стратегической отрасли, как энергетика, должно приниматься политическим руководством государства с подачи ученых и высококвалифицированных специалистов! А население относительно принимаемых государственных решений должно быть грамотно и всесторонне информировано, именно специалистами, без перегибов и инсинуаций.

Как бы там ни было, большинство стран мира наращивает темпы строительства атомных электростанций, делая ставку на использование ядерного топлива. Казахстан пока не использует свой уникальный потенциал наличия огромного количества самого дешёвого топлива для электростанций, надеясь на весьма призрачное первенство в добыче и использовании горючих ископаемых, запасы которых иссякнут в ближайшие десятилетия. К тому времени Казахстан может безвозвратно отстать в развитии технологий ядерной энергетики и будет выступать лишь в качестве сырьевого придатка развитых государств.

В настоящее время Казахстан обладает одной из крупнейших в мире урановой сырьевой базой, которая позволяет обеспечить не только внутренние потребности даже при условии максимального развития атомной энергетики, но и выводит республику в ряды наиболее крупных мировых экспортёров урана на международном рынке. Перспективы восполнения и наращивания минерально-сырьевой базы урана в Казахстане существуют реально [3].

Применяемый до 80-х годов прошлого века карьерный (открытый) и шахтный методы добычи урана сейчас не используются. Эти технологии оказалась экономически и экологически не рентабельными. Сейчас применяется экономически выгодный и экологически безопасный метод подземного скважинного выщелачивания (ПСВ) [3].

Особенностью передового метода подземного скважинного выщелачивания (ПСВ) является то, что в этом случае исключается целая технологическая цепочка: вскрытие рудных тел и образование отвалов, взрывные работы, транспортировка горной массы, дробление и измельчение урановых руд, сортировка на радиометрических контрольных станциях - (РКС) и дробление. Сохраняется только один гидрометаллургический процесс переработки урановых руд - выщелачивание урана. К Кому же весь это процесс перенесен с поверхности под землю. Понятно, насколько этот метод экономичнее и экологичнее всех существующих ранее; на поверхности земли не остается никаких отходов (карьеров, отвалов, временных дорог, обогатительных фабрик, большегрузных машин и других технологических объектов). Еще одной важной особенностью метода кислотного выщелачивания является применение процесса избирательного выщелачивания бедных урановых руд. [4].

Экологическое преимущество метода подземного скважинного выщелачивания (ПСВ) заключается в том, что «добыча урана» происходит под землей путем растворения природных минералов урана и откачки его на поверхность. Все отходы «производства» остаются под землей!

ПСВ даёт возможность получать продуктивный раствор непосредственно на месторождении - из откачных скважин. То есть отпадает необходимость проведения самых энергозатратных и губительных для окружающей среды выше перечисленных этапов извлечения полезного компонента из руды.

Данный метод позволяет извлекать полезные компоненты из руд, практически не нарушая экологии, сохраняя даже поверхностный слой почвы и не нарушая гидрогеологическую обстановку в районе. Отсутствие буровзрывных работ, открытых горных выработок, шахтных стволов, отвалов «пустых» пород и некондиционных руд, превращает термин «рудник» в чисто условное понятие [4]. 
Тем не менее, проектами работ по добыче урана предусматривается ежегодное отчисление в среднем - 6,77\% от затрат на добычу на проведение рекультивационных работ после окончания эксплуатации месторождений.

Рекультивация подземных вод на месторождениях не производится, так как многочисленными и многолетними исследованиями доказано, что ПСВ не нарушает природного равновесия в подземной гидросистеме региона. О чистоте этой технологии, как о доказанном факте, имеется заключение Государственной экологической экспертизы РК.

Какие же выводы можно сделать из всего выше сказанного?

1. Современная мировая наука бъёт тревогу: на планету неумолимо надвигается энергетический кризис: запасы нефти не беспредельны; газ - ценнейшее сырьё для химической промышленности и, пожалуй, наряду с нефтью, самая выгодная сегодня экспортная продукция нашего государства. Сжигать эти природные богатства в топках электростанций - это безумие и тупик в развитии энергетики. А сжигание угля создаёт неразрешимые экологические проблемы. Кроме того, большинство функционирующих в республике ТЭС и ГРЭС давно исчерпали свой ресурс и требуют широкомасштабной реконструкции и замены технологического оборудования.

2. В этих условиях ведущие учёные мира категорически утверждают, что, по крайней мере, на ближайшие многие десятилетия атомной энергетике альтернативы нет. Поэтому сеть атомных электростанций в мире стремительно растёт, и будет расти непрерывно. И если некоторые страны (например, Германия) под эйфорию аварии на Фукусима-1 приняли решение отказаться от развития атомной энергетики, то это, скорее всего, их ошибка, и они свое решение вынуждены будут пересмотреть! Сейчас в мире на АЭС вырабатывается примерно $20 \%$ от всей электроэнергии, а в ряде передовых стран c высокоразвитой экономикой АЭС превратились в основу национальной энергетики. Эти страны не подвержены топливным кризисам и их экономика слабо зависит от колебаний цен на мировом рынке нефти и газа.

3. Атомная энергетика экологически самая чистая и безопасная при нормальной эксплуатации, но в случае серьёзных аварий - очень опасная. При этом выход один и он очевиден - сделать опасное безопасным. На этом пути были большие ошибки, но есть огромный опыт и успехи. Например, современные российские энергоблоки ВВЭР-1000 - это энергоблоки, которые не только соответствуют всем мировым стандартам, но и превосходят зарубежные аналоги по основным показателям, в том числе - по безопасности.

4. Есть большой опыт высокоразвитых стран, как Великобритания, Франция, США, Япония. Их энергетика фактически уже немыслима без АЭС, которые превратились в основу национальной экономики. США имеют 105 ядерных реакторов, небольшая по территории Франция - 59, Россия -29.

5. Казахстану нельзя больше уповать на свои фантастические запасы органического топлива, а срочно принимать меры, чтобы заранее подготовить свою экономику к неизбежному топливному голоду. Необходимо срочно начать подготовку высококвалифицированных кадров, становление которых как специалистов не ограничивается получением высшего образования, а занимает на практике как минимум 8 - 10 лет.

6. Необходимо активно убеждать всё население об исключительной перспективности ядерной энергетики, пропагандировать надежность и экологичность современных и, тем более, будущих ядерных энергетических установок. Подобные публикации ученых и специалистов в СМИ внесут 
значительный вклад в достижение перечисленных выше целей, и позволит гражданам получить доступную информацию о наиболее острых проблемах и задачах передовой науки и технического прогресса.

7. В нашей республике сосредоточено около $21 \%$ мировых разведанных запасов урана - это второе место в мире. Уникальные месторождения урана позволяют нашей республике уверенно занимать ведущее место по добыче самого дешёвого топлива с дальнейшей перспективой на ее увеличение. Наши отечественные специалисты обладают бесценным опытом и технологиями добычи уранового сырья практически при любой морфологии рудных залежей и тел до глубин порядка 1000 метров. У нас развита собственная уранодобывающая и перерабатывающая промышленность с полным ядерно-топливным циклом, что позволит обеспечить отечественную атомную энергетику сырьем, произведенным внутри страны. В Казахстане сохранилась уникальная научная база для исследований в области ядерной физики, квалифицированные научные и технические кадры. Успешно эксплуатируются в научных целях три исследовательских ядерных реактора.

8. Только развитие атомной энергетики будет способствовать обеспечению энергетической безопасности и независимости Казахстана. А этот факт в условиях возможных колебаний цен на сырье и прогнозируемого многократного роста потребностей в электроэнергии является большим плюсом. Ядерная энергетика позволит увеличить объем производимой энергии, не нарушая при этом экологический баланс. Развитие атомной энергетики объективно приведет к повышению технологического уровня отечественного машиностроения, укреплению научно-технического потенциала страны и созданию новых высокотехнологичных отраслей экономики. В результате строительства АЭС в стране будет изменена структура экспорта в направлении увеличения доли высокотехнологичной продукции - электроэнергии и реакторного топлива.

9. Стабильность тарифов на электроэнергию в течение длительного периода времени, которую обеспечивает атомная энергетика, создаст дополнительную инвестиционную привлекательность Казахстана.

После длительных раздумий, обсуждений и переговоров дело о развитии атомной энергетики в Казахстане, похоже, сдвинулось с «мертвой точки». На данный момент Лидером государства уже даны поручения о начале практической реализации проекта по строительству АЭС в Казахстане. В настоящее время начинаются работы по техникоэкономическому обоснованию (ТЭО) и выбору площадки для строительства первой АЭС.

\section{References:}

1. Батырбеков Г.А. Маханов У. М. Резникова Р. А. «Сопоставимый анализ проектов современных атомных электростанций и ядерных топливных циклов разных стран». Алматы.2004.

2. Берикболов Б.Р., Каюков П. Г. и др. Отчёт по теме: «Оценка воздействия добычи урана методом подземного выщелачивания на окружающую среду на отрабатываемых месторождениях Северный Карамурун, Канжуган, Уванас и Мынкудук». Алматы 2002.

3. Бугенов Е.С. Василевский О.В. Школьник В.С. «Теория и практика производства урана и его соединений». Алматы. 2012.

4. Жунисбеков С. Турсынов А.А. «Сравнительный эколого-экономический анализ основных методов добычи урана». Тараз. 2011. 
5. Радиационная безопасность. Международное агентство по атомной энергии, (МАГАТЭ). Вена 1996.

6. Рихванов Л.П. «Радиоактивные элементы в окружающей среде и проблемы радиоэкологии». Томск. 2009.

7. Поляков В.И. «Радиоэкологические проблемы нефтепромыслов. Международная конференция «Радиоактивность и радиоактивные элементы в среде обитания человека». Доклад. ГНЦ НИИР, Дмитровоград.1996.

8. Школьник В.С. «Перспективы энергетики Казахстана в свете мировых тенденций энергетического развития». Астана. 2008.

9. Учебно-методическое руководство по радиоэкологии и обращению с радиоактивными отходами для условий Казахстана. Алматы. Волковгеология. 2002. 